International Journal of Biology, Pharmacy and Allied Seiences (IJBPAS)

'A Bridge Betueen Caboratory and QRendo'

WwW.ijbpas.com

\title{
STUDY ON REDUCTION OF MICROBIAL CONTENT OF EYE OINTMENT BY DIFFERENT DOSES OF GAMMA RADIATIONS
}

\author{
ASLAM F ${ }^{* 1}$, ZUBAIR H ${ }^{1}$, BAJWA SI ${ }^{2}$ AND NAZ S ${ }^{1}$ \\ 1: Department of Biotechnology, Lahore College for Women University, Lahore, Pakistan \\ 2: School of Biological Sciences, University of the Punjab, Pakistan \\ *Corresponding Author: Dr. Farheen Aslam: E Mail: farheenpu@gmail.com; Tel.: \\ +92-42-99203801-9 Ext-277
}

Received 20 ${ }^{\text {th }}$ March 2021; Revised 22 ${ }^{\text {nd }}$ April 2021; Accepted $10^{\text {th }}$ June 2021; Available online $1^{\text {st }}$ Feb. 2022

https://doi.org/10.31032/IJBPAS/2022/11.2.5776

\begin{abstract}
Eye ointment are commonly used to cover eyes infections. Eye ointment must be sterile when prepared. Pseudomonas aeruginosa is very common gram negative bacteria generally found to be present in ophthalmic products. It may cause serious infection of cornea. It can cause complete loss of eye sight in 24-48 hours. Eye ointments are designed to have melting point close to the human body. Eye ointment products are the most successfully sterilized dosage forms by gamma radiation due to their anhydrous nature, low melting point and because of the traditional sterilization method. Samples were purchased from different pharmacies of Lahore. The samples were enriched in nutrient broth and inoculums of these samples were cultured on nutrient agar, MacConkey agar, Potato dextrose Agar to isolate the microbial load present on them. For their identification API E20 strips were used. Upon identification the bacteria identified were bacillus subtilis. The samples were then sent to PARAS for sterilization by gamma radiation from a cobalt 60 source. Three doses of gamma radiation $15 \mathrm{kGy}$, $20 \mathrm{kGy}$ and $25 \mathrm{kGy}$ were applied on these samples, so that the effective dose was optimized at which all the microbial flora is eliminated. The samples were again enriched in nutrient broth and then streaked on nutrient agar plates for presence of microbes separately for each dose. Samples showed no microbial growth at minimum dose which is $15 \mathrm{kGy}$. So $15 \mathrm{kGy}$ is the optimized dose at which microbial load on eye ointment will be completely eliminated.
\end{abstract}

Keywords: Gamma irradiation; Sterilization; microbial load; Ophthalmic ointment 


\section{INTRODUCTION}

Any process that effectively kills the microorganisms like bacteria, viruses, fungi is known as sterilization. The different methods of sterilization are: dry heat sterilization, Steam sterilization, Filteration sterilization, ethylene oxide sterilization (EtO) and gamma sterilization [1].

A variety of Pharmaceutical products has been sterilized by using gamma radiation from cobalt-60 source [2].

Ointments are fairly safe, well tolerated and the ocular contact time is increased by its application. Natural fats (both animal and vegetable) were used extensively in the past. Among the more common vehicles were lard, olive oil and wool-fat. The major problem regarding these natural fats is that most tend to be unsafe and to become rancid quickly, thereby often producing marked ocular irritation. Ointments provide a means for prolonging drug retention in the conjunctival and tear film. For centuries Ointments in several forms have been used for ocular conditions [3].

Ophthalmic ointment products are probably among the most successfully sterilized dosage forms by gamma radiation, mainly due to four reasons. First, the most effective thermal sterilization cannot be applied to ointment products because of their low melting point and the subsequent precipitation of the suspended drug. Second, the aseptic process, a traditional sterilization method for ophthalmic ointments, involves the possibility of secondary contamination and excessive costs. Third, the intrinsic nature of strong penetration of gamma rays enables gamma sterilization to be the favourable method for terminal sterilization of eye ointments. The fourth reason is the expected stability of drugs in ophthalmic ointments to radiation due to their anhydrous nature.

The ophthalmic ointments are consisted of a petrolatum vehicle and active ingredients. The active ingredients were able to be used as sterile solids [4].

Eye ointments are usually prepared with mixture of wool fat and paraffin. Some formulations are produced on a basis described as plastibase which is a mixture of polythene and paraffin [5]

Desirable characteristics for ointment development include easy manufacturing, not irritating to the eye, causing no excessive blurred vision. Typical manufacturing process for an ophthalmic ointment includes sterilization by ethylene oxide, dry heat or irradiation with gamma irradiation. Antimicrobial preservatives (if required) such as chlorobutanol or parabens are dissolved in a mixture of molten 
petrolatum and mineral oil and cooled to about $40^{\circ} \mathrm{C}$ with continuous mixing to assure homogeneity. Micronized and sterilized active is then added aseptically to the warm sterilized petrolatum mineral oil mixture with continuous mixing until the ointment is homogeneous.

\section{MATERIALS AND METHODS}

Three samples of eye ointments from five different companies were collected. The collected samples were labeled as A, B, C, D, and E. Different techniques were used to isolate microbial flora from eye ointments to check effectiveness of sterilization procedure used during manufacturing. Nutrient Broth (Peptone 5g, Beef Extract $1.5 \mathrm{~g}$, Yeast Extract $1.5 \mathrm{~g}$, Sodium chloride $5 \mathrm{~g}$ ) was used. $1.8 \mathrm{~g}$ of nutrient broth was weighed and added to $225 \mathrm{ml}$ of distilled water in a conical flask. By constant mixing, solution was homogenized and autoclaved at $121^{\circ} \mathrm{C}$ for 15 minutes. It was kept at room temperature and allowed to cool. The tubes were incubated at $37^{\circ} \mathrm{C}$ for 24 hours to check the sterility. After 24 hours incubation $20 \mu \mathrm{l}$ of eye ointment was enriched in the tubes under proper sterilized conditions. and then the tubes were incubated at $37^{\circ} \mathrm{C}$ for 24 hours.

Three growth media were used for enumeration and identification of bacteria and fungi associated with eye ointments.
Nutrient agar (Yeast extract 1.5, Peptic digest of animal tissue, $20 \mathrm{~g}, \mathrm{NaCl} 5 \mathrm{~g}$, Agar $1.5 \mathrm{~g}$, Beef extract $1.5 \mathrm{~g}$ and $\mathrm{pH} 5.6 \pm 0.2$ at $25^{\circ} \mathrm{C}$ ) medium was prepared by dissolving $8.4 \mathrm{~g}$ of nutrient agar in $300 \mathrm{ml}$ of distilled water. By constant mixing the solution was homogenized and then autoclaved at $121^{0} \mathrm{C}$ for 15 minutes. It was then kept at room temperature and allowed to cool. Each Petri dish was poured with $20 \mathrm{ml}$ of sterilized nutrient agar medium and allowed to solidify. The plates were then kept at room temperature for 24 hours to check the sterility. With the help of a micropipette $10 \mu \mathrm{l}$ of one day old nutrient broth enriched with samples was placed at the centre of each petri plate containing nutrient agar medium. After inoculation, petri plates were incubated at $37^{\circ} \mathrm{C}$ for 24 hour to check the microbial load, restreaked on nutrient agar plate for separation of pure colonies.

MacConkey agar for, Gram-negative enteric bacilli isolation, (Peptone 20.0, $\mathrm{NaCl}$ 5.0, Lactose 10.0, Neutral red 0.075, Agar 12.0, Bile salts 5.0 and $\mathrm{pH} 7.4 \pm 0.2$ at $25^{\circ}$ C) medium was prepared by weighing $15.6 \mathrm{~g}$ of MacConkey agar powder in $300 \mathrm{ml}$ distilled water. Then by constant mixing solution was homogenized and then autoclaved at $121^{\circ} \mathrm{C}$ for 15 minutes. Kept the solution at room 
temperature and allowed to cool. $20 \mathrm{~mL}$ sterilized medium poured in each petri plate and allowed to solidify. The plates were kept for 24 hours at room temperature to check the sterility. Then with the help of a sterilized loop $1 \mathrm{ml}$ of nutrient broth enriched with samples were taken out and streaked on the plate containing MacConkey agar medium then the petri plates were incubated at $37^{\circ} \mathrm{C}$ for 24 hour to check the microbial load.

$11.7 \mathrm{~g}$ of potato dextrose powder was weighed and dissolved in $300 \mathrm{ml}$ distilled water. Then by constant mixing solution was homogenized and autoclaved at $121^{\circ} \mathrm{C}$ for 15 minutes. Allow to cool at room temperature. $20 \mathrm{~mL}$ of sterilized medium were poured in each petri plate and allowed to solidify. The plates were then kept for 24 hours at room temperature to check the sterility. Then with the help of a sterilized loop $1 \mathrm{ml}$ of nutrient broth enriched with samples were placed at the potato dextrose agar plate. Then the petri plates were incubated at $37^{\circ} \mathrm{C}$ for 24 hour to check the growth.

Identification tests were performed to determine characterizing aspects of bacteria. After obtaining pure culture bacterial isolates were subjected to gram staining and endospore staining for determination of bacterial cell morphology. For further identification of bacterial isolates, catalase test was performed and the API 20 E method was used, and the tested isolates identified using $20 \mathrm{E}$ analytical profile index.

Three doses 15 kGy, 20 kGy and 25 kGy of gamma radiation were set to irradiate eye ointments. Samples were then sent to PARAS (Pakistan Atomic radiation service) for irradiating.

After irradiation samples were labeled and enriched in the nutrient broth and tubes were incubated at $37^{\circ} \mathrm{C}$ for 24 hours. Then with the help of a pipetter $10 \mathrm{ml}$ of solution was taken and placed on petri plates containing nutrient agar medium then with the help of sterilized loop solution was streaked on the plates. Plates were incubated at $37^{\circ} \mathrm{C}$ for 24 hours, 48 hours and 72 hours to check the microbial load.

\section{RESULTS}

The samples were enriched in nutrient broth and streaked on nutrient agar plate. After 24 hours incubation the colonies observed on the nutrient agar plate were opaque, upraised margins, flat, mycoid, having smooth surface and off white in colour (Table 1). The colonies were then restreaked on nutrient agar plate in order to get the pure colonies.

With the help of a micropipette $1 \mathrm{ml}$ of the solution was pipetted out from the nutrient broth tube and placed at the centre of petri plate and streaked on MacConkey agar 
plate. No microbial growth was observed on plates which showed that gram negative bacteria were absent in all the samples (Table 2).

With the help of a micropipette $1 \mathrm{ml}$ of the solution was pipetted out from the nutrient broth tube and placed at the centre of petri plate and streaked on potato dextrose agar plate. No growth observed on potato dextrose agar plates which showed no fungal spores were present on the samples (Table 3).

From the streaked plate of nutrient agar pure colony was picked and gram staining was done for the identification. The slides observed under the microscope showed gram positive, rods, having purple colour. Endospore staining was done for the identification of endopores which can be useful in classifying bacteria. After the procedure of endospore staining slides observed under microscope showed round spores having green colour.

Analytical Profile Index strips were inoculated with bacterial suspension and were placed in the incubator for 48 hours. Results of API were noted and compared with the characteristic of Bacillus subtilis. Bacillus subtilis catabolizes acetoin, potassium hydroxide $(\mathrm{KOH})$ test negative, oxidase positive, catalase positive, indole negative, and Voges-Proskauer test positive. By comparing all the characteristics it was observed that bacteria were of Bacillus subtilis.

Samples of Eye Ointment taken which contained the colonies. According to the survey of literature three doses of gamma radiation were set to radiate eye ointments manufactured by those companies containing microbial load. Doses were 15 kGy, 20 kGy and 25 kGy. Samples were then sent to PARAS (Pakistan Atomic radiation service) for radiating.

After radiation samples were labeled and enriched in the nutrient broth and tubes were incubated at $37^{\circ} \mathrm{C}$ for 24 hours. Then with the help of a pipetter $10 \mathrm{ml}$ of solution was taken and placed on petri plates containing nutrient agar medium then with the help of sterilized loop solution was streaked on the plates. Plates were incubated at $37^{\circ} \mathrm{C}$ for 24 hours, 48 hours and 72 hours to check the microbial load. Sample irradiated with $15 \mathrm{kGy}$ gamma radiation showed no microbial growth. Hence 15 kGy was optimized as gamma radiation dose for sterilization of eye ointments. 
Table 1: Enumeration of microbes on Nutrient Agar

\begin{tabular}{|c|c|c|c|c|c|c|c|c|c|}
\hline $\begin{array}{c}\text { Compa } \\
\text { nies }\end{array}$ & Cfu/sample & LSD & Shape & Texture & Elevation & Opacity & Colour & Margin & Size \\
\hline $\mathbf{A}$ & 0 & - & - & - & - & - & - & - & - \\
\hline B & $\begin{array}{c}2.1 \times 10^{4} \pm \\
0.632456^{a}\end{array}$ & $\begin{array}{c}2.178812 \\
8297\end{array}$ & Flat & Mycoid & $\begin{array}{c}\text { Not } \\
\text { Elevated }\end{array}$ & Opaque & Off white & Fine & $\begin{array}{l}\text { Large to } \\
\text { moderate }\end{array}$ \\
\hline $\mathrm{C}$ & 0 & - & - & - & - & - & - & - & - \\
\hline D & $\begin{array}{l}2.4 \times 10^{4} \pm \\
0.632456^{\mathrm{a}}\end{array}$ & $\begin{array}{c}2.319523 \\
3834 \\
\end{array}$ & Flat & Mycoid & $\begin{array}{c}\text { Not } \\
\text { Elevated }\end{array}$ & Opaque & Off white & Fine & $\begin{array}{c}\text { Large } \\
\text { tomoderate }\end{array}$ \\
\hline $\mathbf{E}$ & $\mathbf{0}$ & - & - & - & - & - & - & - & - \\
\hline
\end{tabular}

All values are the sum of means of five parallel replicates \pm indicates standard deviations $( \pm$ SD) among replicates. Means followed by different letters in same column differ significantly at $P=0.05$ according to Duncan's new multiple range test

Table 2: Microbial Enumertion on MacConkey Agar

\begin{tabular}{|c|c|c|}
\hline Company & Plate Number & Results \\
\hline \multirow{2}{*}{ B } & 1 & $\begin{array}{c}\text { No growth observed on Mac-Conkey agar plates. This shows that } \\
\text { gram negative microbes were absent. }\end{array}$ \\
\cline { 2 - 3 } & 2 & $\begin{array}{c}\text { No growth observed on Mac-Conkey agar plates. This shows that } \\
\text { gram negative microbes were absent. }\end{array}$ \\
\cline { 2 - 3 } & 3 & $\begin{array}{c}\text { No growth observed on Mac-Conkey agar plates. This shows that } \\
\text { gram negative microbes were absent. }\end{array}$ \\
& 1 & $\begin{array}{c}\text { No growth observed on Mac-Conkey agar plates. This shows that } \\
\text { gram negative microbes were absent. }\end{array}$ \\
& 2 & $\begin{array}{c}\text { No growth observed on Mac-Conkey agar plates. This shows that } \\
\text { gram negative microbes were absent. }\end{array}$ \\
& 3 & $\begin{array}{c}\text { No growth observed on Mac-Conkey agar plates. This shows that } \\
\text { gram negative microbes were absent. }\end{array}$ \\
\cline { 2 - 3 } & &
\end{tabular}

Table 3 ; Microbial Enumertion on Potato Dextrose Agar

\begin{tabular}{|c|c|c|}
\hline Company & Plate Number & Results \\
\hline \multirow{2}{*}{ B } & 1 & $\begin{array}{c}\text { No growth observed on Potato Dextrose Agar plates. This } \\
\text { shows fungal growth absent. }\end{array}$ \\
\cline { 2 - 3 } & 2 & $\begin{array}{c}\text { No growth observed on Potato Dextrose Agar plates. This } \\
\text { shows fungal growth absent }\end{array}$ \\
\cline { 2 - 3 } & 3 & $\begin{array}{c}\text { No growth observed on Potato Dextrose Agar plates. This } \\
\text { shows fungal growth absent }\end{array}$ \\
\hline \multirow{2}{*}{ D } & 1 & $\begin{array}{c}\text { No growth observed on Potato Dextrose Agar plates. This } \\
\text { shows fungal growth absent }\end{array}$ \\
\cline { 2 - 3 } & 2 & $\begin{array}{c}\text { No growth observed on Potato Dextrose Agar plates. This } \\
\text { shows fungal growth absent }\end{array}$ \\
\cline { 2 - 3 } & 3 & $\begin{array}{c}\text { No growth observed on Potato Dextrose Agar plates. This } \\
\text { shows fungal growth absent }\end{array}$ \\
\hline
\end{tabular}

\section{DISCUSSION}

Many eye problems are treated by using eye ointments. They are quite safe to use and the ocular contact time is increased by its application. Ointments should be developed in such a way that they won't be irritating to the eye and they are designed to have a melting point close to the human body temperature. It is very necessary to sterilize the eye ointments because many bacteria were found in ophthalmic products which are streptococcus, staphylococcus, pseudomonas aeroginosa and bacillus subtilis. They can cause blurred vision or many other eye infections if not properly sterilized. Therefore it is so necessary to sterilize the eye ointments to ensure good health. 
Due to four reasons eye ointments are the most successfully sterilized dosage forms by gamma radiation. First, the most effective thermal sterilization cannot be applied to ointment products because of their low melting point and the subsequent precipitation of the suspended drug. Second, the aseptic process, a traditional sterilization method for ophthalmic ointments, involves the possibility of secondary contamination and excessive costs. Third, the intrinsic nature of strong penetration of gamma rays enables gamma sterilization to be the favourable method for terminal sterilization of eye ointments. The fourth reason is the expected stability of drugs in ophthalmic ointments to radiation due to their anhydrous nature [6]. The study was performed to check the sterilization method of the manufacturer of eye ointment by using different microbiological techniques and to check the microbial flora existing on eye ointments. Results showed that the ointments which were sterilized by using gamma radiation had no growth. While other samples contained the microbes. Upon identification the bacteria identified were bacillus subtilis.

Bacteria of the genus Bacillus, are gram positive, aerobic, Spore forming rods they are ubiquitous in the environment. Bacillus subtilisis the most widely studied microorganism have the ability to form a tough protective endospore, allowing microorganisms to tolerate extreme environmental conditions.

38 patients were identified with eye infections caused by bacillus species [7]. Bacillus spp. (Gram-positive) organisms that can infect ocular and adnexal tissues leading to dacryocystitis, conjunctivitis ,keratitis, and iridocyclitis [8].

Bacillus subtilis has emerged as one of the most virulent and destructive ocular pathogens. In 1934 Frangois reviewed reports of 157cases of infection of the eye by "Bacillus subtilis", although the descriptions of the organisms and their infections are suggestive rather of $B$. cereus. The six types of infection, in order of decreasing frequency, were conjunctivitis, panophthalmitis, keratitis, iridocyclitis, dacryocystitis and orbital abscess. Panophthalmitis, usually fulminating, is the most serious of these infections. In recent years $50 \%$ of the cases have followed haematogenous dissemination of the organism. This has led to endogenous endophthalmitis that progressed within $24 \mathrm{~h}$ to panophthalmitis with, characteristically, severe pain, chemosis, periorbital swelling, extreme proptosis, low-grade fever, leucocytosis, ring abscess of the cornea and irreversible loss of vision [9].

The objective of this study was to sterilize the eye ointments by using gamma 
radiation from a cobalt 60 source. Three doses were set according to the literature survey at which there is a possibility of eliminating microbial flora. The results showed that $15 \mathrm{kgy}$ is the appropriate dose of gamma radiation for the sterilization of eye ointments.

\section{CONCLUSION}

Results show that Bacillus subtilis is the most common bacteria found on eye Ointments. In the present study gamma radiation is recommended for the sterilization of the medical products so that their complete sterility can be assured and they can be used safely.

\section{ACKNOWLEDGEMENTS}

The authors are indebted to PARAS foods Lahore for their cooperation and assistance with costing the Irradiation facility.

\section{REFERENCES}

[1] Gopal, N, 1978. Radiation sterilization of pharmaceuticals and polymers, Radiation Physics and Chemistry, 12, 1978, 35-50.

[2] Controulis, J, Lawrence C and Brownell L, 1954. The effect of gamma radiation on some pharmaceutical products, Journal of the American Pharmaceutical Association, 43, 1954, 65-69.
[3] Robin JS and Ellis PP, 1978. Ophthalmic ointments. Survey of Ophthalmology, 22, 1978, 335-340.

[4] Polli GP, Fong DT and Shoop CE, Sterile topical dosage forms I: Laboratory phase, Journal of Pharmaceutical Sciences, 61, 1972, 1078-108.

[5] Harte V, OHanrahan M and Timoney $\mathrm{R}$, Microbial contamination in residues of ophthalmic preparations. International Journal of Pharmaceutics, 1, 1978, 165-171.

[6] Bosela AA, Salamah KK, Alsarra, IA and El-Bagory IM, Reactivity of prednisolone to gamma radiation in aqueous and organic solutions. Journal of Drug Delivery Science and Technology, 20(3), 2010, 225-229.

[7] Sliman, R., Rehm, S. and Shlaes, D. M. 1987. Serious infections caused by Bacillus species. Medicine, 66: 218223.

[8] Hemady R, Zaltas M, Paton B, Foster CS and Baker AS, Bacillusinduced endophthalmitis: new series of 10 cases and review of the literature. British journal of ophthalmology, 74, 1990, 26-29.

[9] Logan N, Bacillus species of medical and veterinary importance. Journal of medical microbiology, 25, 1988, 157165. 